\title{
Infectious salmon anaemia virus replication and induction of alpha interferon in Atlantic salmon erythrocytes
}

\author{
Samuel T Workenhe1, Molly JT Kibenge ${ }^{1}$, Glenda M Wright ${ }^{2}$, \\ Dorota W Wadowska ${ }^{3}$, David B Groman ${ }^{4}$ and Frederick SB Kibenge*1
}

\begin{abstract}
Address: ${ }^{1}$ Department of Pathology and Microbiology, Atlantic Veterinary College, University of Prince Edward Island, 550 University Avenue, Charlottetown, PE. C1A 4P3, Canada, ${ }^{2}$ Department of Biomedical Sciences, Atlantic Veterinary College, University of Prince Edward Island, 550 University Avenue, Charlottetown, PE. C1A 4P3, Canada, ${ }^{3}$ Electron Microscopy Laboratory, Atlantic Veterinary College, University of Prince Edward Island, 550 University Avenue, Charlottetown, PE. C1A 4P3, Canada and ${ }^{4}$ Aquatic Diagnostic Services, Atlantic Veterinary College, University of Prince Edward Island, 550 University Avenue, Charlottetown, PE. C1A 4P3., Canada

Email: Samuel T Workenhe - sworkenhe@upei.ca; Molly JT Kibenge - mkibenge@upei.ca; Glenda M Wright - gwright@upei.ca; Dorota W Wadowska - wadowska@upei.ca; David B Groman - groman@upei.ca; Frederick SB Kibenge* - kibenge@upei.ca

* Corresponding author

Published: 28 February 2008

Virology Journal 2008, 5:36 doi:10.1186/1743-422X-5-36

This article is available from: http://www.virologyj.com/content/5/I/36

(c) 2008 Workenhe et al; licensee BioMed Central Ltd.

This is an Open Access article distributed under the terms of the Creative Commons Attribution License (http://creativecommons.org/licenses/by/2.0), which permits unrestricted use, distribution, and reproduction in any medium, provided the original work is properly cited.

Received: 7 January 2008

Accepted: 28 February 2008
\end{abstract}

\begin{abstract}
Background: Infectious salmon anaemia (ISA) virus (ISAV), which causes ISA in marine-farmed Atlantic salmon, is an orthomyxovirus belonging to the genus Isavirus, family Orthomyxoviridae. ISAV agglutinates erythrocytes of several fish species and it is generally accepted that the ISAV receptor destroying enzyme dissolves this haemagglutination except for Atlantic salmon erythrocytes. Recent work indicates that ISAV isolates that are able to elute from Atlantic salmon erythrocytes cause low mortality in challenge experiments using Atlantic salmon. Previous work on ISAVinduced haemagglutination using the highly pathogenic ISAV strain NBISAOI and the low pathogenic ISAV strain RPC/NB-04-085I, showed endocytosis of NBISA0I but not RPC/NB-04-085I. Realtime RT-PCR was used to assess the viral RNA levels in the ISAV-induced haemagglutination reaction samples, and we observed a slight increase in viral RNA transcripts by 36 hours in the haemagglutination reaction with NBISAOI virus when the experiment was terminated. However, a longer sampling interval was considered necessary to confirm ISAV replication in fish erythrocytes and to determine if the infected cells mounted any innate immune response. This study examined the possible ISAV replication and Type I interferon (IFN) system gene induction in Atlantic salmon erythrocytes following ISAV haemagglutination.
\end{abstract}

Results: Haemagglutination assays were performed using Atlantic salmon erythrocytes and one haemagglutination unit of the two ISAV strains, NBISAOI and RPC/NB-04-085I, of differing genotypes and pathogenicities. Haemagglutination induced by the highly pathogenic NBISAOI but not the low pathogenic RPC/NB-04-085I resulted in productive infection as evidenced by increased ISAV segment 8 transcripts and increase in the median tissue culture infectious dose $\left(T C I D_{50}\right)$ by 5 days of incubation. Moreover, reverse transcription (RT) quantitative PCR used to compare mRNA levels of key Type I IFN system genes in erythrocyte lysates of haemagglutination reactions with the two ISAV strains showed a higher relative fold increase of IFN- $\alpha$ in NBISAOI haemagglutinations compared to RPC/NB-04-085-I haemagglutinations (33.0 - 44.26 relative fold increase compared to 11.29). Erythrocytes exposed to heat-inactivated virus or to polyinosinic:polycytidylic acid (polyl:C) or to L-I5 medium alone (negative control assays) had 
minimal late induction (<3.5 relative fold increase) of STATI and/or ISG I 5 and Mx genes, whereas erythrocytes exposed to UV-inactivated virus lacked any cytokine induction.

\begin{abstract}
Conclusion: ISAV-induced haemagglutination by a highly pathogenic virus strain results in virus uptake and productive infection of Atlantic salmon erythrocytes accompanied by significant induction of IFN- $\alpha$. This study also highlights the critical role of ISAV strain variation in the initial stages of the virus-cell interaction during haemagglutination, and possibly in the pathogenesis of ISA. Moreover, the study shows for the first time that fish erythrocytes immunologically respond to ISAV infection.
\end{abstract}

\section{Background}

Infectious salmon anaemia (ISA) is a highly fatal viral disease affecting marine-farmed Atlantic salmon (Salmo salar L). This fish disease is caused by ISA virus (ISAV), a fish orthomyxovirus assigned to the genus Isavirus within the family Orthomyxoviridae [1]. The ISAV strains are enveloped particles of 90-140 nm diameter with surface projections consisting of a combined haemagglutininesterase (HE) protein [2] and a separate fusion (F) protein [3]. The genome is composed of eight segments of linear, single-stranded negative sense RNA ranging in length from 1.0 to $2.4 \mathrm{~kb}$ with a total molecular size of approximately $14.3 \mathrm{~kb}[4]$.

The clinical disease caused by ISAV in marine-farmed Atlantic salmon is associated with anaemia [5], which is hypothesized to be linked with uptake of virus-coated erythrocytes by immune cells [6]. The fish erythrocytes would probably be coated with ISAV through interaction of the cellular sialic acid receptors and the viral HE glycoprotein as occurs during the haemagglutination reaction. ISAV haemagglutination of fish erythrocytes, similar to influenza A virus haemagglutination of avian and mammalian erythrocytes, involves three independent phenomena: [1] adsorption of viruses at the erythrocyte membrane, [2] subsequent elution [7-9], which is not always complete, and [3] uptake of viruses by the erythrocytes $[10,11]$. For ISAV, elution from erythrocytes was originally reported to occur with erythrocytes of several fish species except Atlantic salmon [7] in which the virus causes a natural clinical disease (as reviewed in [12]). However, recent work indicates that ISAV isolates that are able to elute from Atlantic salmon erythrocytes cause low mortality in challenge experiments using Atlantic salmon [13]. In our previous work on ISAV-induced haemagglutination using the highly pathogenic NBISA01 and the low pathogenic RPC/NB 04-0851, only NBISA01 was taken up by the erythrocytes from Atlantic salmon and rainbow trout (Oncorhynchus mykiss) [11]. In contrast, the uptake of influenza A virus by avian and mammalian erythrocytes via pinocytosis was non-specific [10] indicating a lack of involvement of virus strain-specific differences such as pathogenicity level. This suggested to us that the lack of dissolution of pathogenic ISAV-induced haemagglutina- tion of Atlantic salmon erythrocytes favours endocytosis of the virus particles by the erythrocytes [11] and this phenomenon may contribute to the anaemia in ISA.

Members of the family Orthomyxoviridae are known to have a nuclear replication phase [1]. Enucleated BS-C-1 cells have been shown to be non-permissive for replication of influenza A viruses [14]. By inference, mature mammalian erythrocytes, which are enucleated, are also non-permissive for replication of influenza A viruses. In the case of the nucleated avian (turkey or chicken) erythrocytes, haemagglutination by avian influenza A virus resulted only in de novo synthesis of viral proteins but not production of new infectious virus [15]. We previously used real-time RT-PCR to assess the viral RNA levels in the ISAV-induced haemagglutination reaction samples, and observed a slight increase in viral RNA transcripts by 36 hours in the haemagglutination reaction with NBISA01 virus when the experiment was terminated [11]. However, a longer sampling interval was considered necessary to confirm ISAV replication in fish erythrocytes and to determine if the infected cells mounted any innate immune response.

The Type I IFN system constitutes the major antiviral defence mechanism in the innate immune system of mammals as well as fish [16]. Most cell types are able to detect viral replication dsRNA intermediates and respond by secretion of IFN, which then uses the JAK/STAT signalling pathway to stimulate induction of the components of the Type I IFN system genes such as Mx, ISG15 and STAT1 [17]. Atlantic salmon organs and the macrophage-like fish cell line TO [18] respond to ISAV infection by up-regulating the expression of key Type I IFN system genes [19]. The limited immunological studies on the nucleated fish erythrocytes suggest that they possess a certain level of immune functions; the mature erythrocyte populations of rainbow trout were shown to surround macrophages phagocytosing Candida albicans and to secrete cytokinelike macrophage inhibitory factors [20]. However, there is no report of IFN induction in intact erythrocytes either in fish or avian or mammalian species. 
The goal of this study was to determine whether ISAV uptake by fish erythrocytes results in a productive infection and, if so, whether there is any effect of differences in the pathogenicity level of the virus on the cellular response. This information is needed to further clarify the pathogenesis of the clinical disease in fish. In order to obtain information on the putative associated innate immune response in erythrocytes, we used reverse transcription (RT) quantitative PCR assays with SYBR Green chemistry to evaluate mRNA levels of Type I IFN system genes IFN- $\alpha, M x$, ISG15, STAT1 and PKZ at regular intervals up to 5 days following virus-induced haemagglutination.

\section{Results \\ ISAV replicates in Atlantic salmon erythrocytes}

Haemagglutination by pathogenic ISAV is associated with endocytosis of the virus particles, which seems to be consistent with virus infection [11]. To determine whether ISAV endocytosis by fish erythrocytes results in a productive infection, and to further analyze the differences between virus strains of differing pathogenicity, we monitored the haemagglutination assays with NBISA01 and RPC/NB-04-085-1 strains for transcription of viral genes on ISAV segment 8 using real-time RT-PCR. In the previous report, the haemagglutination assays were carried out with $10^{9.75} \mathrm{TCID}_{50} / \mathrm{ml}$ for NBISA01 and $10^{4.25} \mathrm{TCID}_{50} / \mathrm{ml}$ for RPC/NB-04-085-1 [11]. In order to use an equal number of haemagglutination (HA) units in the present study, the HA units of the stock virus preparations were determined, and all haemagglutination assays used $1 \mathrm{HA}$ unit of virus preparation. For NBISA01, 1 HA unit contained $10^{8.45} \mathrm{TCID}_{50}$ and had a cycle threshold $(\mathrm{Ct})$ value of 26.57, whereas for RPC/NB-04-085-1, 1 HA unit contained $10^{5.75} \mathrm{TCID}_{50}$ and had a Ct value of 20.39. Thus, the present study, by using the standard $1 \mathrm{HA}$ unit in haemagglutination assays, had less NBISA01 virus but more RPC/ NB-04-085-1 virus content in each haemagglutination reaction than in our previous study [11]. It was possible to maintain the erythrocytes viable for up to 5 days in hae- magglutination assays in the present study by changing the medium of the haemagglutination assay from PBS to L-15 growth medium. The real-time RT-PCR data for quantification of viral transcripts are presented in Table 1. All the Ct values were confirmed to be for positive amplicons by melting curve analysis. Agarose gel electrophoresis of the RT-PCR products also confirmed virus-specific amplification for NBISA01 and RPC/NB-04-085-1, whereas Atlantic salmon erythrocytes without virus, which were incubated in L-15 medium alongside the haemagglutinations as a negative control showed no virusspecific amplification by both melting curve analysis and agarose gel electrophoresis (data not shown). The Ct values for the highly pathogenic NBISA01 strain show a steady decline from the 0 hour $(26.57 \pm 0.14)$ to day 5 $(20.48 \pm 0.29)$ indicating an increase in viral gene transcription. To confirm if the decrease in Ct value was from newly synthesized viral mRNA we used oligodT primers for CDNA synthesis followed by real-time PCR amplification. A similar decrease in Ct value from 0 hour $(22.22 \pm$ $0.05)$ to day $5(19.29 \pm 0.12)$ was observed. In this case, the Ct value of 22.22 at time 0 , at which no viral mRNA should be present, was attributed to residual transcripts in the viral inocula which were cell culture lysates. For a PCR reaction with $100 \%$ efficiency, a $3.3 \mathrm{Ct}$ difference between two samples is equal to a 10 -fold difference in starting sample concentration [21]. The F5/R5 primer pair used in the present study has an amplification efficiency of $96.842 \%$. Thus the changes in the $\mathrm{Ct}$ values for NBISA01 at each sampling point beginning at day 2 (for the onestep RT-PCR using F5/R5) or day 3 (for two-step RT-PCR with RT primed with oligodT and PCR primed using F5/ R5) corresponded to more than 10-fold increase in amplicons in the starting sample concentrations from that of the 0 hour, suggesting that there was de novo synthesis of viral RNA in the erythrocytes of Atlantic salmon. In contrast, the low pathogenic RPC/NB-04-085-1 strain showed no significant change in the $\mathrm{Ct}$ values for any time point (Table 1), indicating absence of virus replication.

Table I: Transcript levels of viral genes on ISAV segment 8 in extended haemagglutination assays $\mathbf{}$

\begin{tabular}{llll}
\hline Sampling points in days & \multicolumn{2}{c}{ NBISA0I haemagglutination } & RPC/NB-04-085-I haemagglutination \\
\cline { 2 - 4 } & $\begin{array}{l}\text { One-step RT-PCR with F5/R5 primer } \\
\text { pair }\end{array}$ & $\begin{array}{l}\text { RT with oligodT primer \& PCR with F5/ } \\
\text { R5 primer pair }\end{array}$ & $\begin{array}{l}\text { One-step RT-PCR with F5/R5 primer } \\
\text { pair }\end{array}$ \\
\hline 0 & $26.57 \pm 0.14$ & $22.22 \pm 0.05$ & $20.39 \pm 0.21$ \\
1 & $24.43 \pm 0.15$ & $20.63 \pm 0.05$ & $21.23 \pm 0.15$ \\
2 & $22.25 \pm 0.21^{*}$ & $19.40 \pm 0.02$ & $20.46 \pm 0.26$ \\
3 & $21.51 \pm 0.33^{*}$ & $18.31 \pm 0.02^{*}$ & $20.76 \pm 0.36$ \\
4 & $21.04 \pm 0.40^{*}$ & $18.67 \pm 0.27^{*}$ & $20.27 \pm 0.22$ \\
5 & $20.48 \pm 0.29^{*}$ & $19.29 \pm 0.12^{*}$ & $20.55 \pm 0.29$ \\
\hline
\end{tabular}

I $C t$ values are average $\pm S D$ of triplicate observation.

*denotes more than 3.3 Ct difference in the starting sample concentrations from that of the 0 hour. 
We examined if the de novo synthesis of viral RNA by NBISA01 in the erythrocytes of Atlantic salmon was accompanied with production of new infectious virus by titrating the haemagglutination reactions on the TO cell line, which is highly permissive for ISAV $[18,22]$. For this, the haemagglutination reactions were sampled at 0,3 and 5 days post-haemagglutination and 10-fold dilutions of each sample were inoculated on TO cell monolayers in quadruplicate. The 0 hour sample showed a $\operatorname{TCID}_{50}$ of $10^{7.0} \pm 0.433 / \mathrm{ml}$ and day 3 sample showed a $\operatorname{TCID}_{50}$ of $10^{6.92} \pm 0.143 / \mathrm{ml}$ while the day 5 sample had a $\operatorname{TCID}_{50}$ of $10^{7.75} \pm 0.25 / \mathrm{ml}$, demonstrating a $0.75 \log _{10}$ increase in virus titre by day 5 . This indicated a productive infection during ISAV-induced haemagglutination with the highly pathogenic NBISA01 virus. The significant decrease in $\mathrm{Ct}$ value in contrast to the small increase in virus titre is attributed to differences in sensitivity between the two assays used here to demonstrate virus replication, and to the limited viral replication possible during the haemagglutination reaction.

\section{ISAV-induced haemagglutination induces IFN- $\alpha$ in fish erythrocytes}

It is generally accepted that key proteins of the Type I IFN system are induced during ISAV infection but they are unable to inhibit the replication of ISAV in vitro and in vivo [19]. Constitutive expression in CHSE-214 cells of Atlantic salmon IFN-induced Mx1 protein does, however, confer resistance to ISAV [23]. Moreover, recently, the ISAV segment 7 ORF1 product was reported to be an IFN-signalling antagonist that enables the virus to counteract IFN-induced antiviral proteins of the host, a function similar to that of the non-structural (NS1) protein encoded by segment 8 of influenza A virus [24]. To determine whether fish erythrocytes mount any cytokine response to ISAV during haemagglutination, and to show the effect of virus replication on the quality of the response, we used quantitative RT-PCR assays to evaluate mRNA levels of key Type I IFN system genes IFN- $\alpha$, Mx, ISG15, STAT1, and PKZ at regular intervals during haemagglutination reactions using native virus and virus inactivated by exposure either to UV light or to heat. The data are summarized in Figures 1 and 2 . The data show that the highly pathogenic NBISA01 virus had a higher relative fold increase for IFN$\alpha$ transcripts than the less pathogenic RPC/NB-04-085-1 virus that did not replicate in erythrocytes. NBISA01 haemagglutinations showed increased IFN- $\alpha$ transcript levels, with a biphasic peak at day $1(44.26 \pm 1.95)$ and day 3 $(33.0 \pm 5.4)$ (Fig. 1A). In contrast, the RPC/NB-04-085-1 haemagglutinations showed a moderate increase by day 2 $(11.29 \pm 2.59)$ (Fig. 1B). NBISA01 induced haemagglutinations had a statistically significant $(\mathrm{p}<0.05)$ mean fold increase compared to RPC/NB-04-085-1 haemagglutinations at all sampling days except day 4 . The $\mathrm{Mx}$ transcript levels in the NBISA01 haemagglutinations were moderate with a maximum by day $3(8.71 \pm 1.33)$ (Fig. $1 \mathrm{~A})$. Surprisingly the Mx transcript levels in the RPC/NB-04-085-1 haemagglutinations had a statistically significant $(\mathrm{p}<$ $0.05)$ mean fold increase compared to NBISA01 haemagglutinations at all sampling days except day 3. ISG15 transcripts had a similar maximum peak for erythrocytes haemagglutinated with either NBISA01 or RPC/NB-04085-1, except that the peak was by day 3 for NBISA01 where there was a statistically significant mean fold increase compared to RPC/NB-04-085-1. For RPC/NB-04085-1, days 1,4 , and 5 showed statistically significant mean fold increases of ISG15 compared to NBISA01. STAT1 is a signal transducer and activator of transcription involved in the JAK/STAT signalling for IFN response (reviewed in [17]). NBISA01 haemagglutinations showed up-regulation of STAT1 by day 3 (7.42 \pm 0.98$)$. In contrast, RPC/NB-04-085-1 haemagglutinations showed a more stable up-regulation from day 2 to day 5 (Figs 1A and 1B) and statistically significant mean fold increase compared to NBISA01 at all the days except day 3. PKR is the most studied member of the alpha subunit of eukaryotic initiation factor- $2 \alpha$ (eIF- $2 \alpha$ )-specific kinase subfamily. It is a serine/threonine characterized by two kinase activities: autophosphorylation in response to binding of dsRNA with high affinity and ssRNA with low affinity, and phosphorylation of eIF- $2 \alpha$ to impair protein synthesis during virus infection [17]. In addition, PKR has a role in signal

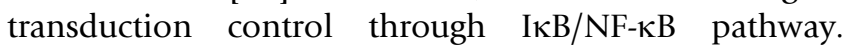
NBISA01 haemagglutination showed increase in PKZ transcript levels by day $3(18.46 \pm 0.79)$ (Fig. 1A). RPC/ NB-04-085-1 haemagglutinations did not show specific amplification for PKZ mRNA (data not shown). The negative control erythrocytes kept in L-15 medium had very minimal induction with a maximum $2.34 \pm 1.21$ relative fold increase of $\mathrm{Mx}$ transcripts by day 5 (Fig. 2). The UVinactivated NBISA01 and RPC/NB-04-085-1 preparations induced very low transcript levels below the 0 hour control (Figs 3A and 3C), whereas the heat-inactivated preparations of both strains showed slight up-regulation of the transcripts (Figs 3B and 3D). These results indicate that fish erythrocytes are immunologically active and produce key Type I IFN genes, particularly IFN- $\alpha$, upon detection of virus associated molecular patterns.

\section{Polyl:C stimulated erythrocytes show minimal induction of Type I IFN system genes}

PolyI:C is a synthetic double stranded (ds)RNA that simulates viral replication nucleic acid intermediates. PolyI:C stimulation of the TO cell line has been shown to induce the expression of key Type I IFN system genes [19]. PolyI:C was included in this study as a direct positive control for inactivated virus preparations. To determine whether fish erythrocytes respond to polyI:C stimulation, Atlantic salmon erythrocytes were exposed to a large dose of polyI:C and incubated as for the haemagglutination 
A

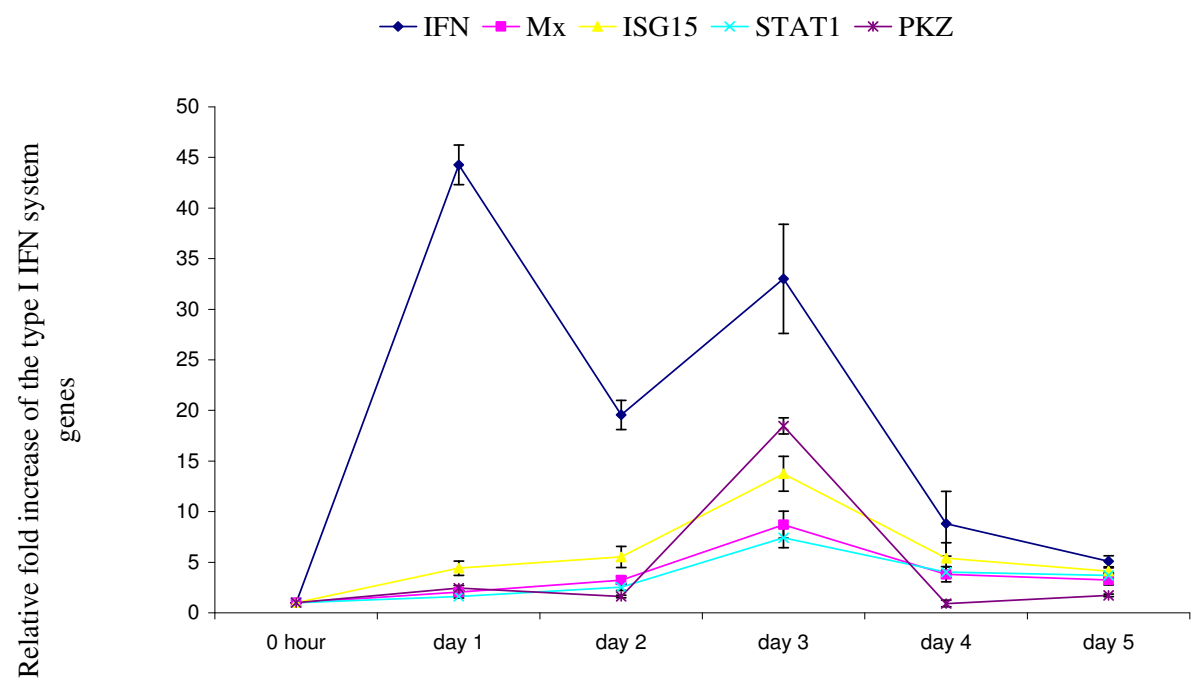

Sampling days after haemagglutination with NBISA01

B

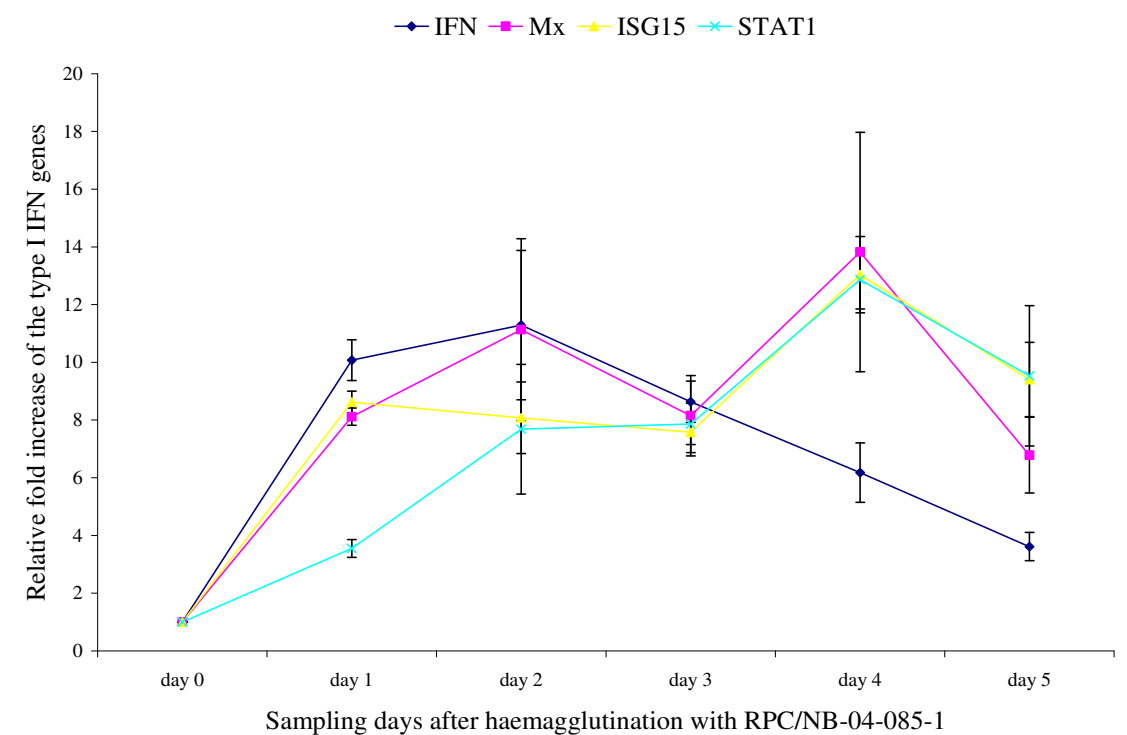

Figure I

mRNA levels of key Type I IFN system genes in Atlantic salmon erythrocytes in response to native virus during haemagglutination assay. Relative fold increase of the key Type I IFN system genes in response to NBISA0I or RPC/ NB-04-085-I haemagglutination calibrated to the I8S rRNA housekeeping gene and the 0 hour control (values are average of a triplicate observation \pm standard deviation): (A) relative fold stimulation of Atlantic salmon IFN genes (SasalFN- $\alpha$ I and SasaIFN- $\alpha 2)$, Mx, ISG I 5 and STATI by NBISAOI virus; (B) relative fold stimulation of Atlantic salmon IFN genes (SasalFN- $\alpha$ I and SasalFN- $\alpha 2$ ), Mx, ISG I 5 and STATI by RPC/NB-04-085-I. 


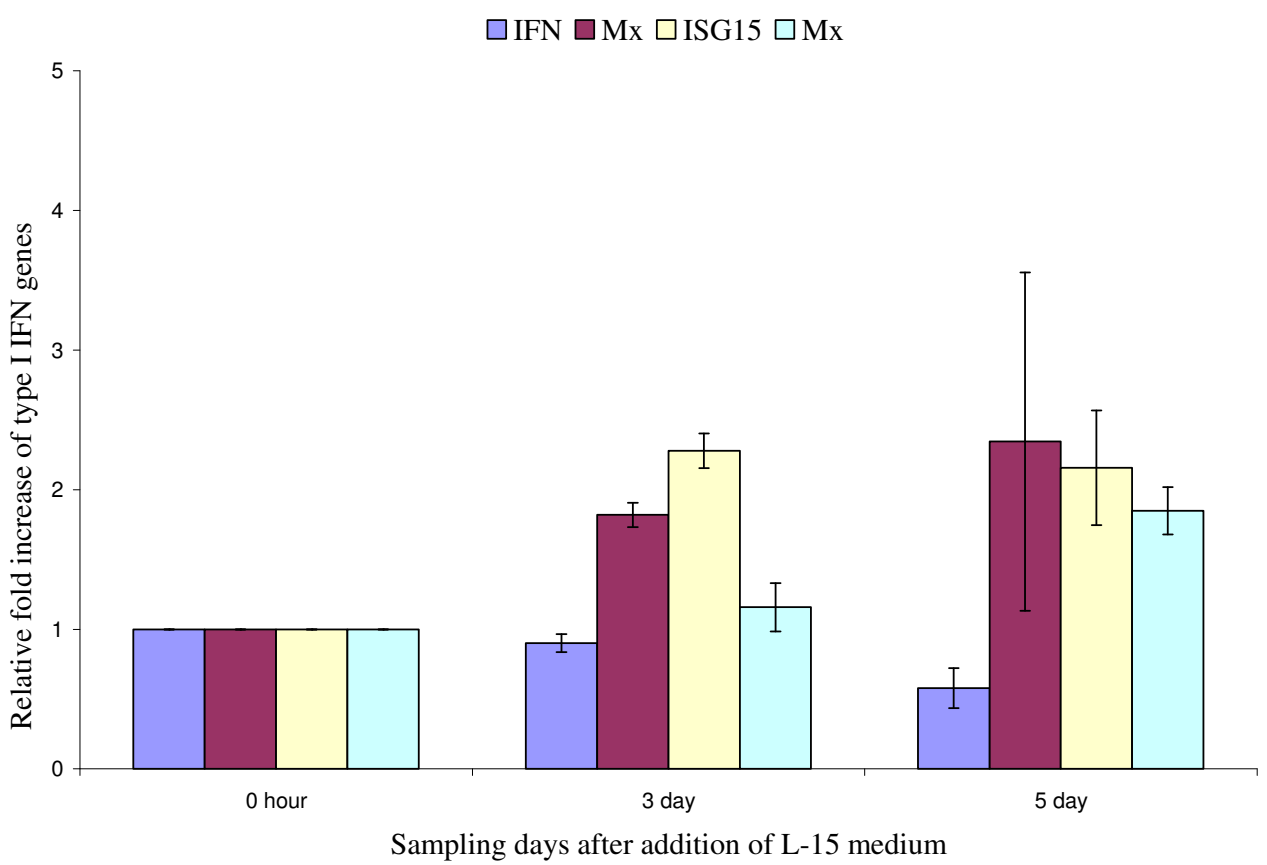

Figure 2

mRNA levels of key Type I IFN system genes in Atlantic salmon erythrocytes in L-I 5 medium (negative control for haemagglutination assay). Relative fold stimulation of the key Type I IFN system genes in Atlantic salmon erythrocytes when virus is not present; i.e., in response to L-I5 medium alone (negative control) calibrated to the I8S rRNA housekeeping gene and the 0 hour control (values are average of a triplicate observation \pm standard deviation): Atlantic salmon IFN genes (SasalFN- $\alpha$ I and SasalFN- $\alpha 2$ ), Mx, ISGI 5 and STATI in negative control erythrocytes.

reactions. As shown in Figure 4, there was only minimal induction of the genes investigated except for ISG15 and Mx by 72 hours after stimulation. These results show that, unlike TO cells, Atlantic salmon erythrocytes do not efficiently respond to polyI:C stimulation. However, the response was similar to that of erythrocytes exposed to heat-inactivated ISAV or to L-15 medium alone (negative control assays).

\section{Discussion}

Two models of haemagglutination-infection phenotypes have been proposed to account for the anaemia associated with the clinical disease due to ISAV infection in fish. The first model is that anaemia in the clinical disease is due to uptake by immune cells of fish erythrocytes coated with ISAV [6], and the receptor destroying enzyme (RDE) activity, which is related to the pathogenicity of the virus [13], allows the virus to elute from fish erythrocytes except those of Atlantic salmon [7]. An alternative model is that failure of ISAV to elute from Atlantic salmon erythrocytes favours virus infection of the erythrocytes, which might result in cell death, and this combination is related to the pathogenicity of the virus [11]. Such a haemagglutination-infection phenotype is fundamentally different from haemagglutination by avian and mammalian orthomyxo- viruses, and may be indicative of a different pathogenesis for the fish orthomyxovirus.

In the present study we set up haemagglutination assays in L-15 growth medium to compare two phenomena (elution and uptake) of the ISAV-induced haemagglutination of Atlantic salmon erythrocytes between virus strains of differing pathogenicities. We found remarkable differences in virus replication and quality of cytokine response in the fish erythrocytes. Real-time quantitative RT-PCR was used to assess the viral RNA levels (i.e., both vRNA and viral mRNA) in the haemagglutination reaction samples. Only the Ct values for the NBISA01 haemagglutinations showed any decrease from the 0 hour to day 5. This decrease was evident even when oligodT primers were used for cDNA synthesis, confirming that there was de novo synthesis of virus genes in the erythrocytes. However, there are relatively long stretches of adenosine residues in the ISAV target gene that could allow detections of vRNA as well. The RPC/NB-04-085-1 haemagglutinations showed no changes in the $\mathrm{Ct}$ values at any sampling time point, indicating that the low pathogenic virus did not replicate in erythrocytes. Moreover, using virus titrations in the TO cell line, it was shown that NBISA01 haemagglutinations resulted in a productive infection. The 
A

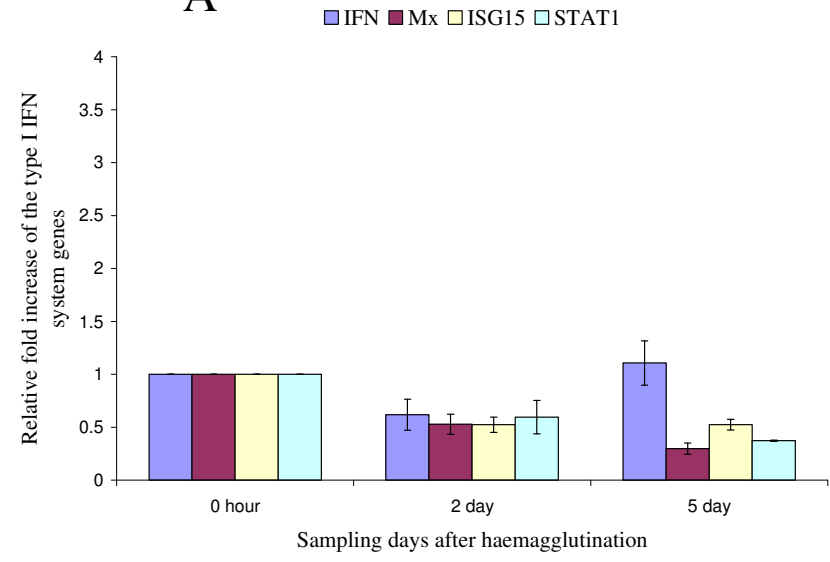

$\square$ IFN $\square$ Mx $\square I S G 15 \square$ STAT1

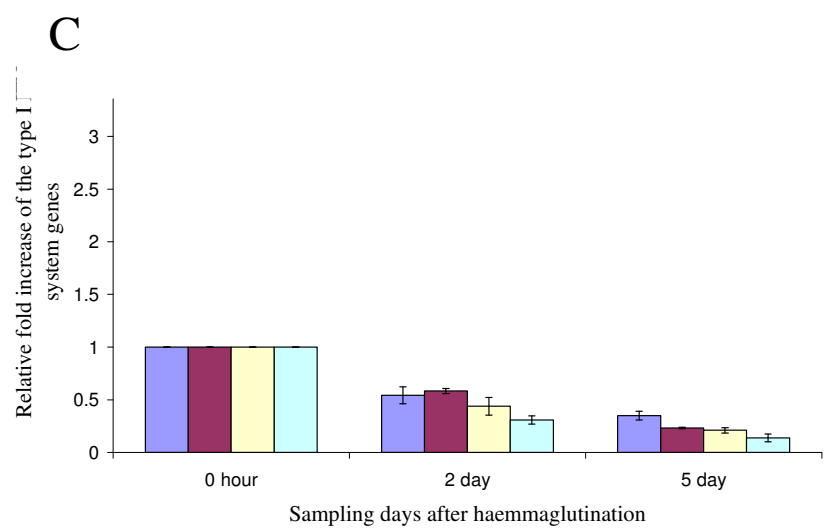

B

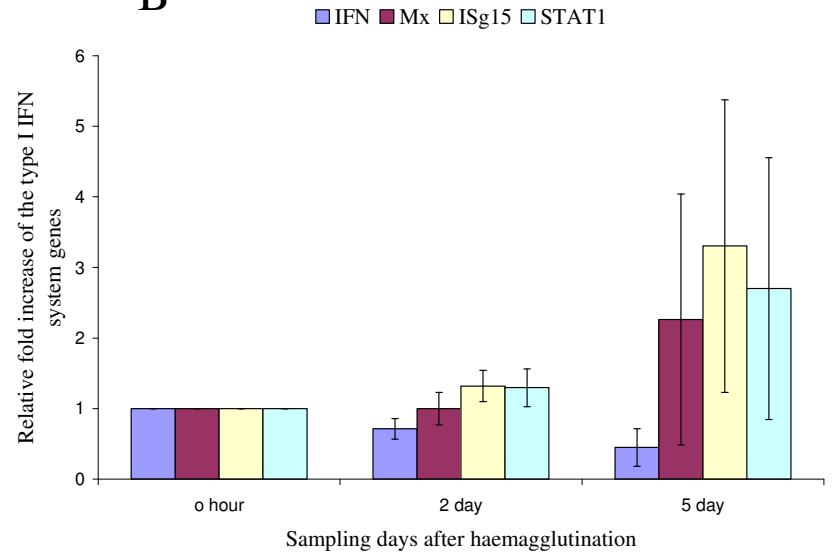

D

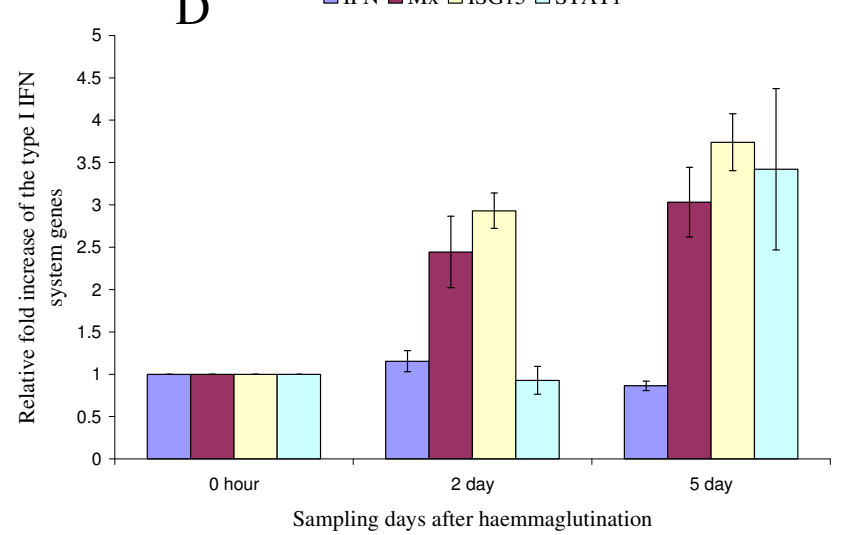

Figure 3

mRNA levels of key Type I IFN system genes in Atlantic salmon erythrocytes in response to inactivated virus during haemagglutination assay. Relative fold increase of the key Type I IFN system genes calibrated to the I8S rRNA housekeeping gene and the 0 hour control (values are average of a triplicate observation \pm standard deviation): (A) UV-inactivated NBISAOI; (B) heat-inactivated NBISAOI; (C) UV-inactivated RPC/NB-04-085-I; and (D) heat inactivated RPC/NB-04085-I haemagglutination.

increase in virus titre between day 0 and day 5 was only $10^{0.75} \mathrm{TCID}_{50}$ in contrast to the 10 -fold increase in the viral transcript levels detected by real-time RT-PCR within the same samples. This may be due to three factors: [1] the lower sensitivity of the virus titration in TO cell line compared to real-time RT-PCR, [2] the fact that real-time RTPCR also detects non infectious or defective particles which the TCID ${ }_{50}$ does not, and [3] the fact that the virus replication associated with haemagglutination involved only a single cycle of virus replication as multiple haemag- glutination events were unlikely. It is interesting to note that avian erythrocytes (which have a dormant nucleus, in contrast to the complete nucleus in fish erythrocytes) also demonstrate virus uptake during haemagglutination by influenza A virus and show de novo synthesis of viral proteins but not production of new infectious virus particles [5] whereas mammalian erythrocytes that do not have a nucleus have completely lost the capacity for virus replication during influenza A virus-induced haemagglutination. 


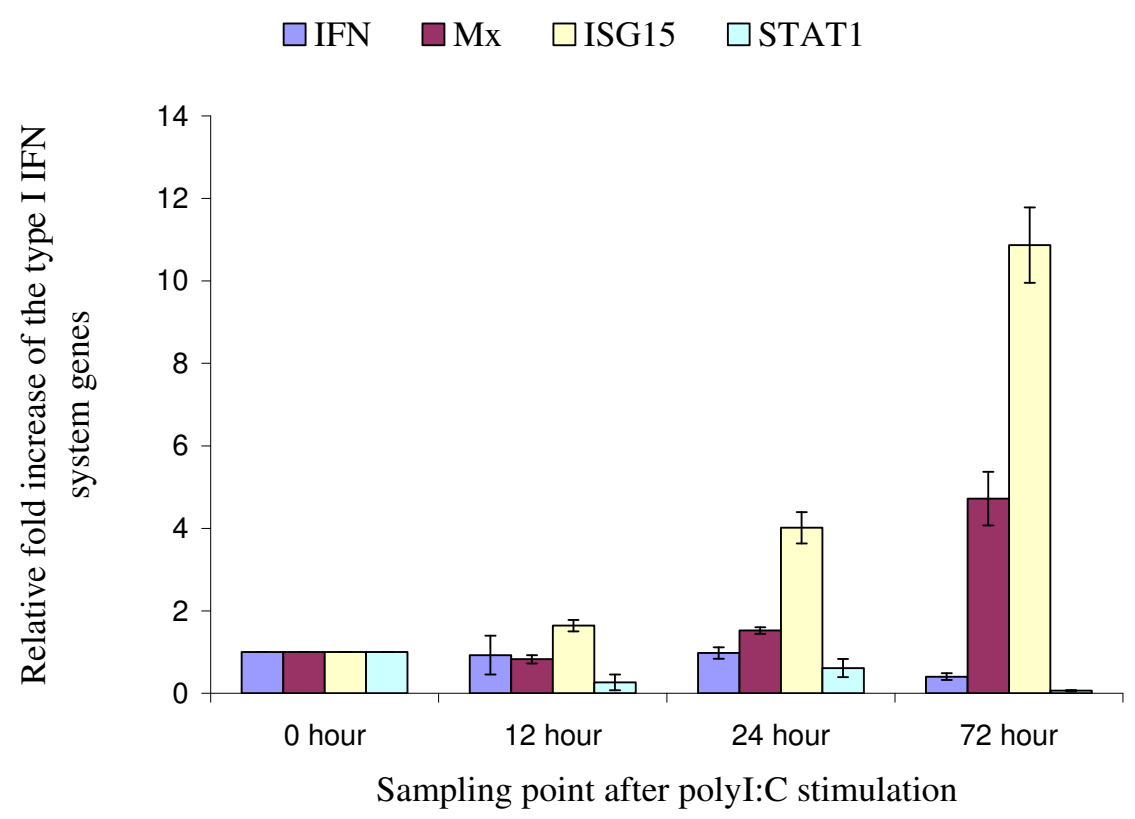

Figure 4

mRNA levels of key Type I IFN system genes in Atlantic salmon erythrocytes in response to Polyl:C stimulation. Relative fold increase of the key Type I IFN system genes in response to polyl:C stimulation calibrated to the I8S rRNA housekeeping gene and the 0 hour control (values are average of a triplicate observation \pm standard deviation).

In addition to virus replication in haemagglutinations induced by the highly pathogenic NBISA01 strain, we found that there was also a higher relative fold increase of IFN- $\alpha$ transcripts than with the less pathogenic RPC/NB 04-085-1 strain which did not replicate in erythrocytes. The induction of the IFN- $\alpha$ gene closely followed the increase of NBISA01 transcripts in that by day 1 the viral transcripts started to increase simultaneously with the first peak of IFN- $\alpha$ transcripts. The NBISA01 haemagglutinations showed a pattern of fold increase with a peak of IFN$\alpha$ and Mx transcripts for a shorter period of time. This pattern of induction is not continuous like the inductions in TO cells infected with ISAV [19]. This may be due to differences between the cell cycle of TO cells (which actively multiply) and erythrocytes (which do not multiply) in combination with the single cycle of virus replication that probably occurs during haemagglutination in contrast to multiple cycles of infection possible in TO cells. For the NBISA01 haemagglutinations in the present study, the level of IFN- $\alpha$ appeared to have a transient biphasic peak at 1 and 3 days post-haemagglutination.

Both the UV- and heat-inactivated preparations of both NBISA01 and RPC/NB-04-085-1 viruses and the L-15 medium assay (negative control) showed no haemagglutination. The UV-inactivated viruses also showed no induction of type I IFN system genes whereas the heatinactivated viruses and the L-15 medium assay showed induction of the type I IFN system genes by day 5 similar to those due to polyI:C stimulation by day 3 . The absence of haemagglutination in the UV-inactivated viruses was unexpected since the inactivation was directed towards the viral genome and not the surface glycoproteins required for haemagglutination. One possible explanation is that the UV lamp generated sufficient heat over the 18 hours of exposure to contribute to the denaturation of the virus surface glycoproteins. In contrast, the heat inactivation alone had no effect on the viral ssRNA genome but probably even disrupted the structural viral proteins so that the virus RNA was exposed and easily detected by the erythrocyte viral pattern recognition receptors so as to induce the observed minimal induction of the Type I IFN system genes. Alternatively, these minimal responses were non-specific since they were also seen with L-15 medium alone (negative control assays).

STAT-1 expression has been studied in other fish species including rainbow trout [25] but this is the first study to investigate STAT1 expression in Atlantic salmon. It appears that induction of STAT1 is not as highly responsive to IFN induced by virus infection as the other component genes of the Type I IFN system in that the fold increase was low compared to the other genes studied. This could be related to the multifunctional role of this transcription factor. 
The NBISA01 haemagglutination showed a moderate relative fold increase of PKZ transcripts. PKR gene has been characterized in rainbow trout [26], and crucian carp [27]. PKR is one of the antiviral proteins of the IFN system [17]. For Atlantic salmon, only the sequence of a Z-DNA binding eIF- $2 \alpha$ kinase is available in the GeneBank database. In crucian carp cells, PKR mRNA has been shown to be upregulated in response to either IFN protein treatment or virus infection. Moreover, in rainbow trout PKR has been shown to be activated to phosphorylate eIF- $2 \alpha$ in response to polyI:C stimulation and virus infection. It is very interesting that Atlantic salmon erythrocytes showed expression of PKZ gene, albeit moderate, in response to haemagglutination with a pathogenic ISAV strain.

In the present work the RT quantitative PCR data showed varying levels of induction of key Type I IFN system genes IFN- $\alpha, M x$, ISG15, STAT1, and PKZ upon haemagglutination of erythrocytes by the highly pathogenic NBISA01 virus. This virus induced significantly high relative fold increase in IFN- $\alpha$ transcripts compared to the RPC/NB-04085-1 virus although both viruses had similar levels of induction of Mx, ISG15 and STAT1. The slight Type I IFN system response with RPC/NB-04-085-1 haemagglutinations which involve only virus adsorption but no endocytosis [11] and no replication is an interesting observation. Various viral pathogen recognition receptors are involved in the detection of viral pathogen associated molecular patterns such as dsRNA, ssRNA, DNA, and viral glycoproteins like haemagglutinin proteins. In the case of human cytomegalovirus [28], herpes simplex [29] and human immunodeficiency virus [30], peripheral mononuclear cells have been shown to induce Type I IFN independent of virus replication, purely by the viral glycoproteins. Thus the low level Type I IFN system gene induction detected in the present study for the low pathogenic RPC/NB-04-0851 virus could possibly be associated with the detection of the viral HE protein during haemagglutination.

PolyI:C is a synthetic dsRNA that is detected either by the RNA helicases or the Toll-like receptor 3 (TLR3) to activate the transcription of type I IFN system genes (reviewed in [16]). This has been shown in the macrophage-like Atlantic salmon TO cell line [19]. Stimulation of erythrocytes with polyI:C did not, however, result in induction of Type I IFN genes even with a polyI:C dose 10 times that used elsewhere [19]. It was previously reported that CHSE-214 cells incubated with polyI:C show no expression of $\mathrm{Mx}$ [31], probably because of inefficient response to polyI:C stimulation. In the present study, NBISA01 endocytosis and replication in Atlantic salmon erythrocytes resulted in up-regulation of the IFN- $\alpha$ gene possibly by detection of the viral molecular patterns by the erythrocytes. Thus the minimal induction of the Type I IFN genes in fish erythro- cytes by polyI:C could be due to inefficient membrane transport activity of erythrocytes.

\section{Conclusion}

In conclusion, we report here that ISAV-induced haemagglutination by a pathogenic virus strain results in virus uptake and productive infection of Atlantic salmon erythrocytes accompanied by significant induction of IFN- $\alpha$. This study also highlights the critical role of ISAV strain variation in the initial stages of the virus-cell interaction during haemagglutination, and possibly in the pathogenesis of ISA. Moreover, the study shows for the first time that fish erythrocytes immunologically respond to ISAV infection.

\section{Methods \\ Viruses}

Two ISAV isolates of differing genotypes and pathogenicities were used. NBISA01 is a highly pathogenic strain belonging to the North American genotype, whereas RPC/ NB 04-085-1 is a low pathogenic strain of the European genotype found in eastern Canada and its HE protein places it in a unique, highly polymorphic region (HPR) group [32]. The two isolates have variations in the amino acid sequence of the HPR region with amino acid deletions of 13 and 17 amino acids for RPC/NB-04-085-1 and NBISA01, respectively [33]. The viruses were propagated in the TO cell line [18] and the cell lysates were titrated on TO cell monolayers as previously described [34] prior to use in the subsequent studies.

\section{Virus inactivation}

The viruses were inactivated by using either UV light or heat treatment. UV inactivation of ISAV was carried out with a germicidal UV lamp (G30T8 with 30 Watt and 36 inch length, and a UV intensity of $125 \mu \mathrm{W} / \mathrm{cm}^{2}$ at 1 meter from the lamp) suspended in a biological safety cabinet (Class II A/B3 BSC, Thermo Forma) following the procedure reported by Oye and Rimstad [35], with minor modifications. Briefly, $20.0 \mathrm{mls}$ of virus suspension in a 4-well cell culture plate were placed $10 \mathrm{~cm}$ from the UV lamp. The plate was left open under UV-exposure for 18 hours. Heat inactivation of ISAV was performed by incubating $1.0 \mathrm{ml}$ of the virus suspension in a $1.5-\mathrm{ml}$ microfuge tube at $56^{\circ} \mathrm{C}$ for 5 minutes. Complete inactivation of virus by both methods was confirmed by titration in TO cell monolayers [34] before use in the haemagglutination reactions.

\section{Haemagglutination assays}

Atlantic salmon erythrocytes were collected from specific pathogen free 100 g-Atlantic salmon using EDTA-coated Vacutainer $^{\circledast}$ tubes. In preliminary experiments, the washed erythrocytes suspended in phosphate buffered saline (PBS) were not viable beyond 48 hours. Therefore, 
common fish cell line growth media, Leibovitz's L-15 (Invitrogen) and Hanks minimum essential medium (BioWhittaker) (HMEM), were tested to identify one that better maintained erythrocyte viability. Using the Trypan blue dye exclusion test, we found that erythrocytes resuspended in L-15 growth medium had lower cell deaths, and those surviving maintained a normal shape in contrast to erythrocytes in HMEM growth medium which were shrunken. In subsequent experiments, the erythrocytes were washed and then resuspended in L-15 medium supplemented with $10 \%$ foetal bovine serum, $2 \mathrm{mM} \mathrm{L}$ glutamine, $100 \mathrm{IU} / \mathrm{ml}$ penicillin $\mathrm{G}, 100 \mu \mathrm{g} \mathrm{ml}^{-1}$ streptomycin, and $0.25 \mu \mathrm{g} \mathrm{ml}^{-1}$ amphotericin B. For determining the haemagglutination (HA) units of the stock virus preparations, haemagglutination reactions were set up using $50 \mu \mathrm{l}$ of two-fold dilutions of the two virus isolates and 50 $\mu \mathrm{l}$ of $1 \%$ erythrocytes [36]. The haemagglutination was set using four wells for each virus dilution; 1 HA unit was defined as the highest virus dilution that induced haemagglutination in four wells within $1 \mathrm{hr}$ at room temperature. Subsequent haemagglutination reactions used 1 HA unit in $50 \mu \mathrm{l}$ of virus preparation $50 \mu \mathrm{l}$ of $1 \%$ erythrocytes in L15 growth medium. The sealed plates were kept at room temperature for one hour, and then transferred to $16^{\circ} \mathrm{C}$ for the extended incubation until sampled.

\section{Polyl:C stimulation of Atlantic salmon erythrocytes}

Washed Atlantic salmon erythrocytes were resuspended in L-15 medium consisting of 10\% FBS, 2 mM L-glutamine, $100 \mathrm{IU}$ ml-1 penicillin $\mathrm{G}, 100 \mu \mathrm{g}$ ml-1 streptomycin, and $0.25 \mu \mathrm{g} \mathrm{ml}-1$ amphotericin $\mathrm{B}$, and polyinosinic:polycytidylic acid (polyI:C) (Amersham Biosciences) at a final concentration of $30 \mu \mathrm{g} \mathrm{ml}-1$. One hundred microliters of $1 \%$ erythrocyte suspension was added to each well of the haemagglutination plate and incubated at $16^{\circ} \mathrm{C}$. The preparations were sampled after 12, 24, and 72 hours.

\section{Detection of cytokine induction and virus replication using real-time RT-PCR with SYBR Green chemistry}

Total RNA from the haemagglutination samples was extracted from $375 \mu$ l of homogeneous erythrocyte suspensions using $1.25 \mathrm{ml}$ of TRIZOL Reagent (Invitrogen). RNA extraction was performed from two separate samples at each sampling point, which were then pooled before DNase treatment using the DNase treatment kit (Roche) prior to RT-PCR amplification.

For quantification of the Type I IFN system genes and viral RNA, first strand cDNA synthesis was done using the Transcriptor reverse transcriptase first strand cDNA synthesis kit (Roche). The cDNA synthesis used 125 ng of total RNA in a master mix consisting of $4 \mu$ of $5 x$ RT reaction buffer, $2 \mu \mathrm{l}$ of dNTP mix $(200 \mu \mathrm{M}), 2 \mu \mathrm{l}$ of random hexamer (600 $\mu \mathrm{M})$ or oligodT $(0.8 \mu \mathrm{g} / \mu \mathrm{l}), 0.5 \mu \mathrm{l}$ RNase inhibitor (40 U/ $\mu \mathrm{l}), 0.5 \mu \mathrm{l}$ of Transcriptor reverse transcriptase $(20 \mathrm{U} / \mu \mathrm{l})$, and nuclease free water adjusted to a final volume for 20 $\mu \mathrm{l}$. The RT step was programmed at $25^{\circ} \mathrm{C}$ for 10 minutes followed by $55^{\circ} \mathrm{C}$ for 30 minutes and a final enzyme denaturation for 5 minutes at $85^{\circ} \mathrm{C}$. Real-time PCR used first strand cDNA template with LightCycler FastStart DNA Master SYBR Green I (Roche) in the LightCycler (LC) 1.2 (Roche). The PCR primer pairs used are listed in Table 2; those for $18 \mathrm{~S}$ rRNA, IFN- $\alpha, \mathrm{Mx}$, and ISG-15 are published [19], and the STAT-1 primer pair was described in Workenhe [37]. The PKZ (a Z-DNA binding orthologue of the mammalian double stranded RNA binding PKR) primer was designed using the coding sequence of Atlantic salmon Z-DNA binding eIF-2 $\alpha$ kinase (GenBank Accession \# DQ182560). The IFN gene primer set is designed in the common region of the two IFN- $\alpha$ subtypes, $\alpha 1$ and $\alpha 2$ [38]. The $20 \mu \mathrm{l}$ PCR reaction consisted of $2 \mu \mathrm{l}$ of undiluted cDNA for all genes except $18 \mathrm{~S}$ rRNA (which was diluted $1: 1000)$ and $18 \mu \mathrm{l}$ of the master mix prepared using $0.5 \mu \mathrm{l}$ of the $10 \mu \mathrm{M}$ of the forward and reverse primers (a final concentration of $0.25 \mu \mathrm{M}), 2 \mu \mathrm{l}$ of the LC SYBR Green I DNA Master mix, $1.6 \mu \mathrm{l}$ of the stock $25 \mathrm{mM} \mathrm{MgCl}_{2}$ (a final concentration of $0.003 \mu \mathrm{M}$ ), and $13.4 \mu \mathrm{l}$ of nuclease free water. The real time PCR programme for amplifying PKZ gene had a master mix consisting of $12.8 \mu$ l of water, 2.4 $\mu \mathrm{l}$ of $25 \mathrm{mM} \mathrm{MgCl}_{2}$ (a final concentration of $0.004 \mu \mathrm{M}$ ), $0.4 \mu \mathrm{l}$ of the $10 \mu \mathrm{M}$ forward and reverse primer, and $2 \mu \mathrm{l}$ of SYBR Green master mix. The real-time PCR cycling conditions consisted of an initial denaturation at $95^{\circ} \mathrm{C}$ for 10 minutes to activate the hot-start polymerase, followed by 40 cycles of $95^{\circ} \mathrm{C}$ for $5 \mathrm{~s}, 59^{\circ} \mathrm{C}$ for $10 \mathrm{~s}\left(60^{\circ} \mathrm{C}\right.$ for the PKZ gene), $72^{\circ} \mathrm{C}$ for $10 \mathrm{~s}$, and detection at $80^{\circ} \mathrm{C}$ for $2 \mathrm{~s}$. The cycle threshold $(\mathrm{Ct})$ values, the number of cycles run in real-time RT-PCR when the fluorescence in the sample crosses a threshold value (background) and amplification enters a log-linear phase, were analyzed using LightCycler software version 3.5 (Roche). Melting curve analysis with the same software was performed from $70^{\circ} \mathrm{C}$ to $95^{\circ} \mathrm{C}$ in $0.1^{\circ} \mathrm{C} / \mathrm{s}$ increments to verify the specificity of the amplicons so as to interpret SYBR Green fluorescence data. For determining amplification efficiency of each primer set (Table 2), standard curves were generated using two-fold dilutions of cDNA run in triplicates for six consecutive dilutions. Each sampling point was run in triplicate and the stability of the 18S rRNA, used as housekeeping gene, was followed. The $\mathrm{Ct}$ values of positive amplicons were then analyzed using the Pfaffl method for relative quantification in real-time RT-PCR [39] as previously used elsewhere [19], to get relative fold increase of the Type I IFN genes at each sampling point calibrated to the house keeping gene and normalized with the 0 hour control. To test if the difference in mean relative fold induction between the two virus isolates at each sampling point was statistically significant, data were initially checked for equality of variance using F- test in Microsoft Excel spread sheet. Then 
Table 2: The oligonucleotide primers, amplicon length and amplification efficiency of the real time RT-PCR primers amplifying IFN, Mx, I8S, ISG 15 and STATI genes

\begin{tabular}{llll}
\hline Primer name & Primer sequence & Amplicon length (bp) & Amplification efficiency \\
\hline As IFN Fwd' & TGCAGTATGCAGAGCGTGTG & 100 & 1.83 \\
As IFN Rev' & TCTCCTCCCATCTGGTCCAG & 77 & 1.88 \\
As Mx Fwd & TGCAACCACAGAGGCTTTGAA & & 1.86 \\
As Mx Rev & GGCTTGGTCAGGATGCCTAAT & 60 & 1.83 \\
As I8S Fwd & TGTGCCGCTAGAGGTGAAATT & 100 & 1.82 \\
As I8S Rev & GCAAATGCTTTCGCTTTCG & 100 & 1.913 \\
As ISG I5 Fwd & CTGAAAACGAAAGGGCCA & 101 & \\
As ISGI5 Rev & GCAGGGACTCCCTCCTTGTT & & \\
As STATI Fwd & TGTCTGTTGGCTCAGTTGCG & & \\
As STATI Rev & GAAATTGATGCTGTGGCGTCT & & \\
As PKZ Fwd & AGATAGCGAAGGCTGTTGGA & & \\
As PKZ Rev & TGGTTTGTCTGGTGTTGCAT & & \\
\hline
\end{tabular}

IPrimer amplifies SasalFN- $\alpha$ I and $\alpha 2$.

the $\mathrm{t}$ - Test was used considering the equality/inequality of variance where applicable [40].

For quantifying the level of viral RNA, real-time RT-PCR was done using the RNA Amplification Kit SYBR Green I (Roche) and the primer pair designed by Devold et al. [41] to amplify $220 \mathrm{bp}$ of the ISAV segment 8 , and previously described for real time RT-PCR [42], with minor modifications. Briefly, the $20 \mu \mathrm{l}$ reaction consisted of $50 \mathrm{ng}$ of total RNA in a master mix prepared using $0.3 \mu \mathrm{l}$ of the $20 \mu \mathrm{M}$ of the forward and reverse primers (final concentration of $0.3 \mu \mathrm{M}), 4 \mu \mathrm{l}$ SYBR Green, $0.2 \mu \mathrm{l}$ LC-RT PCR enzyme mix, $3 \mu \mathrm{l}$ of the $5 \mathrm{x}$ resolution solution, $1.6 \mu \mathrm{l}$ of the $25 \mathrm{mM}$ stock $\mathrm{MgCl}_{2}$ (a final concentration of $0.005 \mu \mathrm{M}$ ), and nuclease free water adjusted to a final volume of $20 \mu \mathrm{l}$. The cycling conditions consisted of one cycle of RT at $55^{\circ} \mathrm{C}$ for $30 \mathrm{~min}$, initial denaturation at $95^{\circ} \mathrm{C}$ for $30 \mathrm{~s} \mathrm{fol}-$ lowed by 50 cycles of $95^{\circ} \mathrm{C}$ for $5 \mathrm{~s}, 59^{\circ} \mathrm{C}$ for $10 \mathrm{~s}, 72^{\circ} \mathrm{C}$ for $10 \mathrm{~s}$, and detection at $80^{\circ} \mathrm{C}$ for $2 \mathrm{~s}$. The Ct values and melting curve data were analyzed using LightCycler software version 3.5 (Roche). Melting curve analysis was performed from $70^{\circ} \mathrm{C}$ to $95^{\circ} \mathrm{C}$ in $0.1^{\circ} \mathrm{C} / \mathrm{s}$ increments to verify the specificity of the amplicons so as to interpret SYBR Green fluorescence data. The amplicons were also run in $1 \%$ agarose gel electrophoresis in $1 \mathrm{x}$ Tris acetate EDTA buffer ( $40 \mathrm{mM}$ Tris acetate and $1 \mathrm{mM}$ EDTA) (Fisher Scientific) and stained with ethidium bromide and photographed under $304 \mathrm{~nm}$ UV light.

\section{Detection of virus replication by titration on TO cell monolayers}

Total cell lysates of the haemagglutination assays (i.e., total virus) were titrated to determine growth cycles of the virus strains in Atlantic salmon erythrocytes. Virus titration utilized serial 10-fold dilutions of the samples ranging from $10^{-1}$ to $10^{-8}$, inoculated on 48 -well cell culture plates containing TO cell monolayers using 4 wells per dilution, from which the median tissue culture infectious dose $\left(\right.$ TCID $\left._{50}\right)$ was determined as previously described [33]. Each sampling point was titrated in triplicate to obtain a standard deviation.

\section{Competing interests}

The author(s) declare that they have no competing interests.

\section{Authors' contributions}

STW conducted all the experiments and wrote the manuscript. MJTK helped in designing the experiments and writing the manuscript. GMW and DWW helped in the initial stages of conceiving the study and edited the manuscript. DBG helped in designing the experiments and edited the manuscript. FSBK conceived the study, coordinated the research, and helped in designing the experiments, writing and editing the manuscript.

\section{Acknowledgements}

This work was supported by the Natural Sciences and Engineering Research Council (NSERC) of Canada Discovery Grant to FSBK. We thank the staff of Aquatic Animal Facility of the Atlantic Veterinary College, especially Vicki Leggo for the kind cooperation and provision of fish for blood collection.

\section{References}

I. Kawaoka Y, Cox NJ, Haller O, Hongo S, Kaverin N, Klenk H-D, Lamb RA, McCauley J, Palese P, Rimstad E, Webster RG: Infectious Salmon Anaemia Virus. In Virus Taxonomy - Eight Report of the International Committee on Taxonomy Viruses Edited by: Fauquet CM, Mayo MA, Maniloff J, Desselberger U, Ball LA. Elsevier Academic Press: New York; 2005:68I-693.

2. Falk K, Asperhaug V, Vlasak R, Endresen $\mathrm{C}$ : Identification and characterization of viral structural proteins of infectious salmon anaemia virus. J Virol 2004, 78:3063-307I.

3. Aspehaug VT, Mikalsen AB, Snow M, Biering E, Villoing S: Characterization of the infectious salmon anaemia virus fusion protein. J Virol 2005, 79: I 2544-I 2553.

4. Clouthier SC, Rector T, Brown NEC, Anderson ED: Genomic organization of infectious salmon anaemia virus. J Gen Virol 2002, 83:42I-428. 
5. Evensen O, Thorud KE, Olsen YA: A morphological study of the gross and microscopic lesions of infectious salmon anaemia in Atlantic salmon (Salmo salar). Res Vet Sci I99|, 5 I:2 I 5-222.

6. Dale OB, Falk K, Kvellestad A: An overview of Infectious Salmon Anemia pathology and suggested pathogenesis. Abstr. Fifth International Symposium on Aquatic Animal Health, California USA 2006.

7. Falk K, Namork E, Rimstad E, Mjaaland S, Dannevig BH: Characterization of infectious salmon anemia virus, an orthomyxo-like virus isolated from Atlantic salmon (Salmo salar L.). J Virol 1997, 71:9016-9023.

8. Hirst GK: The agglutination of red blood cells by allantoic fluid from chick embryos infected with influenza virus. SCience |94I, 94:22-23.

9. Howe C, Lee LT: Virus erythrocyte interactions. Adv Virus Res 1972, I7: I-50.

10. Bossart W, Meyer J, Bienz K: Electron microscopic study on influenza virus hemagglutination: pinocytosis of virions by red cells. Virology 1973, 55:295-298.

II. Workenhe ST, Wadowska DW, Wright GM, Kibenge MJT, Kibenge FSB: Demonstration of infectious salmon anaemia virus (ISAV) endocytosis in erythrocytes of Atlantic salmon. Virol J 2007:4. 13

12. Kibenge FSB, Munir K, Kibenge MJT, Joseph T, Moneke E: Infectious salmon anemia virus: causative agent, pathogenesis and immunity. Ani Hlth Res Rev 2004, 5(I):65-78.

13. Falk K, Dale OB: Experimental evidence indicating that lack of viral receptor destroying enzyme is a major factor for infectious salmon anemia pathogenesis. Abstr. Fifth International Symposium on Aquatic Animal Health, California USA 2006.

14. Follett EAC, Pringle CR, Wunner WH, Skehel JJ: Virus replication in enucleate cells: vesicular stomatitis virus and influenza virus. I Virol 1974, I 3:394-399.

15. Cook RF, Avery J, Dimmock NJ: Infection of chicken erythrocytes with influenza and other viruses. Infect Immun 1979 , 25:396-402.

16. Robertsen B: The interferon system of teleost fish. Fish \& Shellfish Immunol 2006, 20:|72-19|.

17. Samuel CE: Antiviral actions of interferons. Clin Microbiol Rev 200I, I4:778-809.

18. Wergeland HI, Jakobsen RA: A salmonid cell line (TO) for the production of infectious salmon anaemia virus (ISAV). Dis Aquat Organ 200I, 44: 183-190.

19. Kileng $\varnothing$, Brundtland MI, Robertsen B: Infectious salmon anemia virus is a powerful inducer of key genes of the type $I$ interferon system of Atlantic salmon, but is not inhibited by interferon. Fish \& Shellfish Immunol 2006, 23:378-389.

20. Passantino L, Altamura M, Cianciotta A, Jirillo $F$, Ribaud MR, Jirillo $E$ Passantino GF: Maturation of fish erythrocytes coincides with changes in their morphology, enhanced ability to interact with Candida albicans and release of cytokine-like factors active upon autologous macrophages. Immunopharmacology \& Immunotoxicology 2004, 26:73-585.

21. Rasmussen R: Quantification on the LightCycler. In Rapid Cycle Real-time PCR, Methods and Applications Edited by: Meuer S, Wittwer C, Nakagawara K. Springer, Heidelberg; 2001:2I-34.

22. Kibenge FSB, Garate ON, Johnson G, Arriagada R, Kibenge MJT, Wadowska $D$ : Isolation and identification of infectious salmon anaemia virus (ISAV) from Coho salmon in Chile. Dis Aquat Organ 200I, 45:9-18.

23. Kibenge MJT, Munir K, Kibenge FSB: Constitutive expression of Atlantic salmon Mx protein in CHSE-2 I 4 cells confers resistance to infectious salmon anaemia virus. Virol / 2005, 2:75.

24. McBeath AJA, Collet B, Paley R, Duraffour S, Aspehaug V, Biering E, Secombes C], Snow M: Identification of an interferon antagonist protein encoded by segment 7 of infectious salmon anaemia virus. Virus Res 2006, I I 5:176-184.

25. Collet B, Munro SE, Gahlawat S, Acosta F, Garcia J, Roemelt C, Zou J, Secombes CJ, Ellis AE: Infectious pancreatic necrosis virus suppresses type I interferon signalling in rainbow trout gonad cell line but not in Atlantic salmon macrophages. Fish \& Shellfish Immunol 2007, 22:44-56.

26. Garner $Y N$, Joshi B, Jagus R: Characterization of rainbow trout and zebrafish eukaryotic initiation factor $2 \alpha$ and its response to endoplasmic reticulum stress and IPNV infection. Dev \& Comp Immunol 2003, 27:217-23I.
27. Hu C-Y, Zhang Y-B, Huang G-P, Zhang Q-Y, Gui J-F: Molecular cloning and characterisation of a fish PKR-like gene from cultured CAB cells induced by UV-inactivated virus. Fish \& Shell immunol 2004, I7(4):353-366.

28. Boehme KW, Singh J, Perry ST, Compton T: Human cytomegalovirus elicits a coordinated cellular antiviral response via envelope glycoprotein B. J Virol 2004, 78(3): | 202- I2I I.

29. Mossman KL, Ashkar AA: Herpesviruses and the innate immune response. Viral Immunol 2005, I 8:267-28I.

30. Ankel H, Capobianchi MR, Castilletti C, Dianzani F: Interferon induction by HIV glycoprotein I 20: role of the V3 loop. Virology 1994, 205:34-43.

3I. Jensen I, Larsen R, Robertsen B: An antiviral state induced in Chinook salmon embryo cells (CHSE-2 I4) by transfection with the double-stranded RNA poly I:C. Fish \& Shellfish Immunol 2002, 13:367-378.

32. Kibenge FSB, Kibenge MJT, Groman D, McGeachy S: In vivo correlates of infectious salmon anemia virus pathogenesis in fish. J Gen Virol 2006, 87:2645-2652.

33. Kibenge FSB, Kibenge MJT, Wang Y, Qian B, Hariharan S, McGeachy $S$ : Mapping of putative virulence motifs on infectious salmon anaemia virus surface glycoprotein genes. J Gen Virol 2007 , 88:3 $|00-3| I I$.

34. Kibenge FSB, Kibenge MJT, McKenna PK, Stothard P, Marshall R, Cusack RR, McGeachy S: Antigenic variation among isolates of infectious salmon anaemia virus correlates with genetic variation of the viral haemagglutinin gene. J Gen Virol 200I, 82:2869-2879.

35. Øye AK, Rimstad E: Inactivation of infectious salmon anaemia virus, viral haemorrhagic septicaemia virus and infectious pancreatic necrosis virus in water using UVC irradiation. Dis Aquat Organ 200I, 48: I-5.

36. Food and Agricultural Organization of the United Nations [http://www.fao.org/docrep/005/ac802e/ac802e0d.htm\#TopOfPage]

37. Workenhe ST: Expression of type I IFN genes: antiviral Mx and the transcription factors STAT-I and IRF-7. M.Sc. Thesis, University of Tromso, Norway 2006.

38. Bergan V, Steinsvik S, Xu H, Kileng $\varnothing$, Robertsen B: Promoters of type I interferon genes from Atlantic salmon contain two main regulatory regions. FEBS Journal 2006, 273:3893-3906.

39. Pfaffl MW: A new mathematical model for relative quantification in real-time RT-PCR. Nucl Acids Res 200I, 29(9):e45.

40. Richardson BA, Overbaugh J: Basic statistical considerations in virological experiments. J Virol 2005, 79:669-676.

4I. Devold M, Krossøy B, Aspehaug V, Nylund A: Use of RT-PCR for diagnosis of infectious salmon anaemia virus (ISAV) in carrier sea trout Salmo trutta after experimental infection. Dis Aquat Organ 2000, 40(I):9-18.

42. Munir K, Kibenge FSB: Detection of infectious salmon anaemia virus by real-time RT-PCR. J Virol Meth 2004, I I 7( I ):37-47.

Publish with Bio Med Central and every scientist can read your work free of charge

"BioMed Central will be the most significant development for disseminating the results of biomedical research in our lifetime. "

Sir Paul Nurse, Cancer Research UK

Your research papers will be:

- available free of charge to the entire biomedical community

- peer reviewed and published immediately upon acceptance

- cited in PubMed and archived on PubMed Central

- yours - you keep the copyright
BioMedcentral 